\title{
ARCHITECTURES AND SOLUTIONS FOR THE KNOWLEDGE WEB
}

\author{
Enrico Motta \\ Knowledge Media Institute \\ The Open University \\ MiltonKeynes, UK \\ e.motta@open.ac.uk
}

\section{ABSTRACT}

In this presentation I will discuss some of the work currently being carried out at the Knowledge Media Institute (KMi) of The Open University, to support the development of 'semantic' web resources and to enable knowledge sharing and collaboration on the web. I will use the terms 'Semantic Web' and 'Knowledge Web' to refer to the basic semantic infrastructure needed to support interoperability and semantic web services (the Semantic Web), and to the knowledge-intensive services and functionalities that we are developing on top of the Semantic Web, to support knowledge sharing and collaborative work (the Knowledge Web). Work at the semantic web level includes libraries of reusable components for knowledge-intensive systems; ontology editors and servers; next-generation, ontology-based annotation tools; and site and interface ontologies to support knowledge-based generation and filtering of web pages. While the Semantic Web is about semantic infrastructure, tools and resources, the Knowledge Web is by and large about people, processes and organisations and about the integration of 'smart' technology into work-processes. Many of the examples I will present concern technologies in daily use at our lab. For instance, we have an electronic newsletter, Planet, which allows KMi members to quickly inform other KMi members and the external world about important events related to $\mathrm{KMi}$. Planet addresses a basic organisational need: how can knowledge be made available quickly throughout an 
organisation? This knowledge publishing process is enhanced by a number of smart technologies which support semantic search of the archive, personalised views over the newsletter, and the production of intelligent newspaper layouts based on an automatic analysis of the importance of the submitted stories. News publishing is but one way to share knowledge, which accounts for one-off postings. In other cases we may want to support intensive discussions about some artefact, such as an academic paper. Our D3E toolkit provides the basic technology to associate discussion spaces with web resources. In addition, we can augment D3E-based discussion spaces with semantic web technology, to provide additional support for group discussions, such as allowing participants to access relevant resources, in response to semantic queries. Finally, I will also briefly talk about our work on the next generation of digital libraries. This aims at allowing authors and readers to augment digital libraries resources (e.g., an academic paper) with formal statements about the scholarly contribution made by each resource and the conceptual relation between resources in the library (e.g., this paper proposes a theory which builds on the work by author $\mathrm{X}$, or refutes theory $\mathrm{Y}$ proposed by author $Z$, etc..).

\section{References}

Motta E. (2001). The Knowledge Modelling Paradigm in Knowledge Engineering. In S.K. Chang (editor), Handbook of Software Engineering and Knowledge Engineering. World Scientific Pub. Co, 2001. ISBN: 981-02-4973-X

Motta E., Buckingham-Shum, S. and Domingue, J. (2000). Ontology-Driven Document Enrichment: Principles, Tools and Applications. International Journal of HumanComputer Studies, 52(6), pp. 1071-1109.

Buckingham-Shum, S., Motta E. and Domingue, J. (2000). ScholOnto: An Ontology-Based Web Server for Research Documents and Discourse. International Journal of Digital Libraries, 3 (3), August/Sept. 2000, Springer-Verlag

Domingue, J. B. and Motta, E. (2000). Planet-Onto: From News Publishing to Integrated Knowledge Management Support. IEEE Intelligent Systems, 15(3), May-June 2000, pp. 26-32.

Motta E. Reusable Components for Knowledge Models: Principles and Case Studies in Parametric Design. IOS Press, 1999.

Domingue, J. B. and Motta, E. (1999). A Knowledge-Based News Server Supporting Ontology-Driven Story Enrichment and Knowledge Retrieval. In Fensel and Studer (eds), 11th European Workshop on Knowledge Acquistion, Modelling, and Management (EKAW' '99), Springer-Verlag, LNAI 1621.

Stutt, A. and Motta, E. (1998). Knowledge Modelling: An Organic Technology for the Knowledge Age. In Eisenstadt, M. and Vincent, T. (editors), The Knowledge Web, Kogan Press. 